\title{
Protection of Ten-Eyed Bridge in Diyarbakır
}

\author{
Ibrahim Baran Karasin, Ercan Isik \\ Department of Civil Engineering, Faculty of Engineering and Architecture, Bitlis Eren University, \\ e-mail: ibkarasin@beu.edu.tr,eisik@beu.edu.tr
}

\begin{abstract}
Mesopotamia, which is one of the strategical regions of the Middle East, has hosted numerous communities and civilizations since the ancient times of human history. This situation made the region considerably prosperous in terms of historical and cultural heritage. Ten-Eyed Bridge, that is one of the most important historical and cultural symbols of Diyarbakir, having lasted till today, became an example of this prosperous heritage. However, various interventions and deteriorations have occurred in the construction within long time due to the impact of human and nature. Because of the considerable temperature difference arising due to continental climate of the region as well as damages like the change of conditions of use, amortizations in bearing constructional components in contact with water have emerged. In this study, with the purpose of ensuring further future existence of Ten-Eyed Bridge, adopted methods for structural and physical deteriorations and protection works were examined.
\end{abstract}

Keywords: Historic Ten-Eyed Bridge, Heritage Protection, Diyarbakır.

\section{Introduction}

Diyarbakir is located in the north of Mesopotamia called Al-Jazira and in Southeastern Anatolia Region of Turkey. It has a border with Malatya, Elazı ̆̆, Bingöl, Muş, Mardin, Şanlıurfa, Batman and Adiyaman cities. Ten-Eyed Bridge situated in Diyarbakir is a historical bridge that becomes one of the symbols of the city with way of construction, its size, high lancet arched niches passing long water span, pyramidal cone flood splitters. While the bridge is named as "Dicle Bridge" in some sources because of its position on Dicle River, it is termed with three different names like "Ten-Eyed Bridge" due to ten-span and "Silvan Bridge" due to its position being on the old road to Silvan. Dicle River is Turkish name of Tiger River. In spite of the fact that there are different opinions about the year of built of the bridge, there are notions Van Bercheh and Albert Gabriel support and claiming that there was a bridge in this region also in ancient period [1]. In Diyarbakir that came under the domination of Islam in 639 , it is mentioned about epigraph reporting that Umayyad Caliph Hisham started to restore a demolished bridge in 742-743 years but with his death, bridge construction stopped. It is known that the armies of the North of Rum Empire surrounded Diyarbakir in 974 but retreated by failing and they had it demolished as they were going [2]. It is thought that when its location and year of built is considered, the bridge mentioned in the sources is Dicle Bridge.

The closest and most accurate date of built known as year of built of the bridge considered that it was demolished a few times partially or completely then it was rebuilt is understood from epigraph on the bridge. According to the epigraph, Emir Muayyad Devle Kasim Nasir, one of Mervanoglu Ahmed's sons, commanded the construction of bridge, had the Ubayd Bin Sacer do bridge by means of Kadı Ebu'l Hasan Abdulvahid bin Muhammad in 1065. As a result of this information reached with epigraphs, it is understood that the known earliest dated Islamic Bridge is Dicle Bridge [3]. 


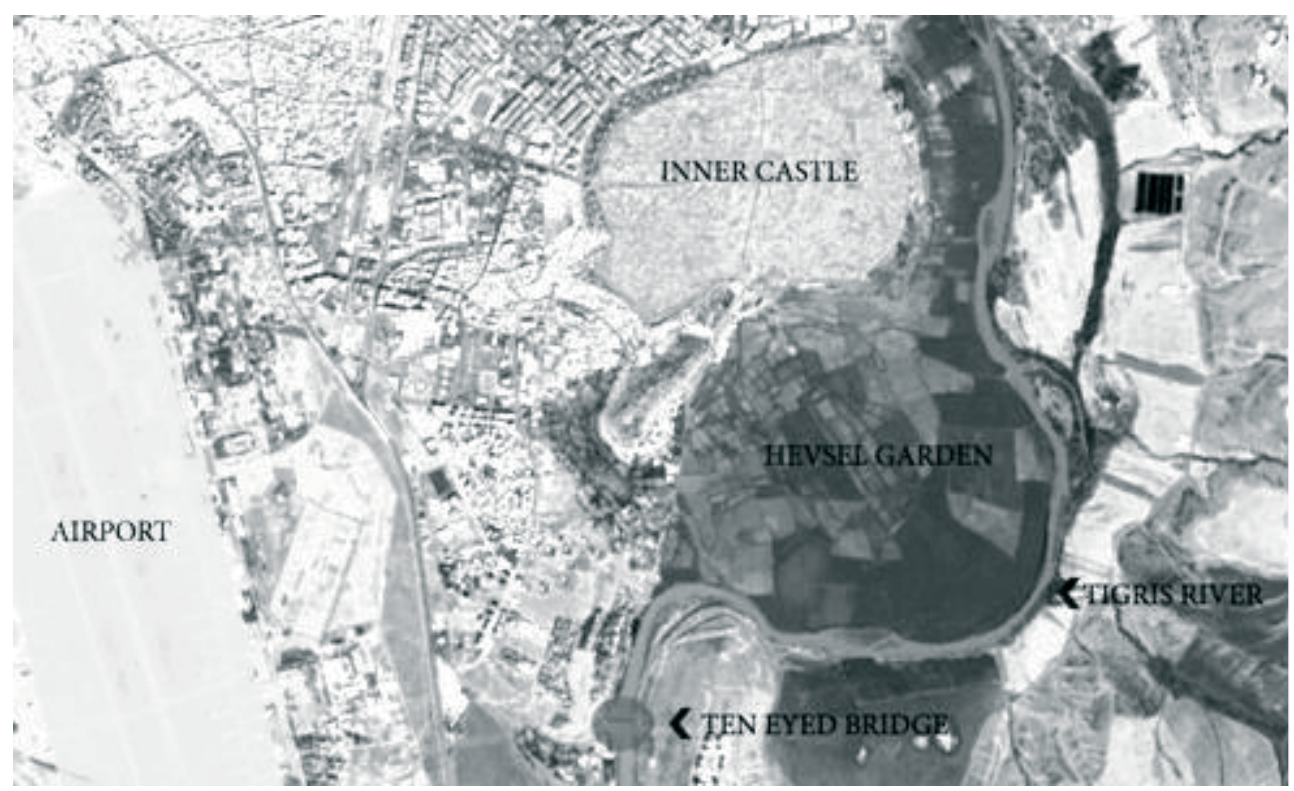

Fig. 1. Localization of the Ten-Eyed Bridge (by means of Google Maps)

The historical Ten-Eyed Bridge that connects many settlements into Diyarbakir in Southeastern Anatolia is located in $3 \mathrm{~km}$ far from city center, Fig. 1.

In the construction of bridge, masonry construction system is used to cross Dicle River. The bridge is $172 \mathrm{~m}$ long. The structure was built using basalt boulders and bricks taken from the quarry which was located of distant about $100 \mathrm{~km}$.

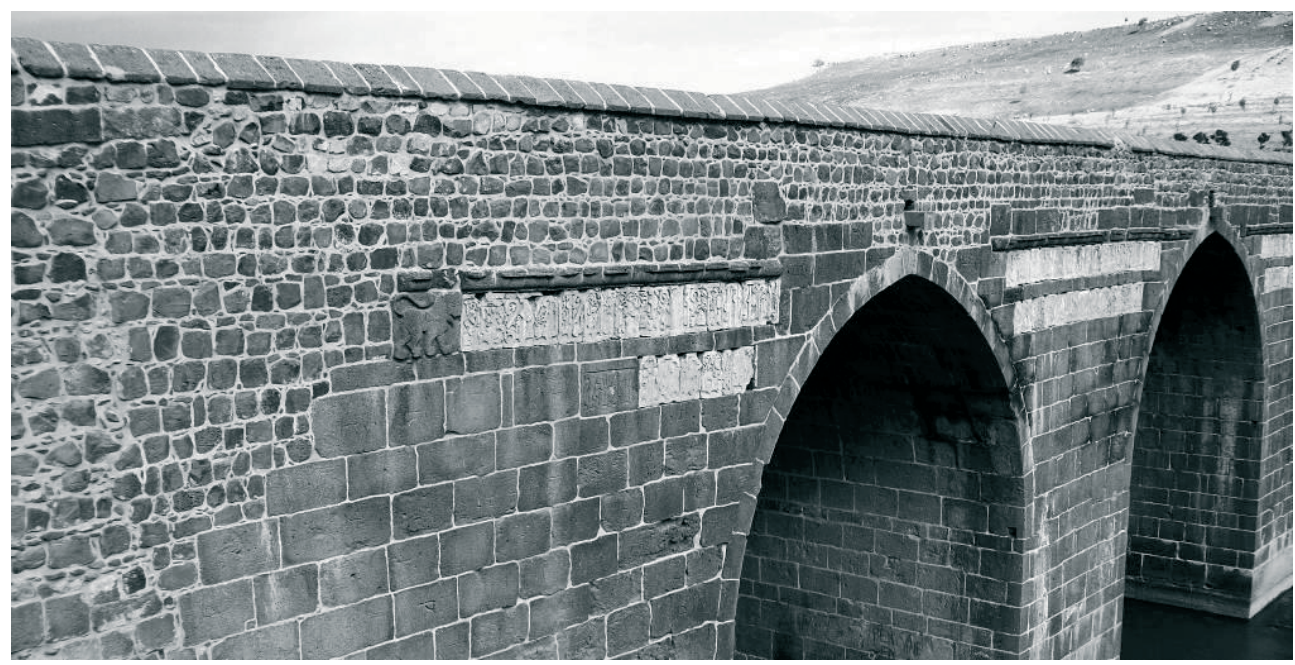

Fig. 2. The Ten-Eyed Bridge view on quotations 
a)

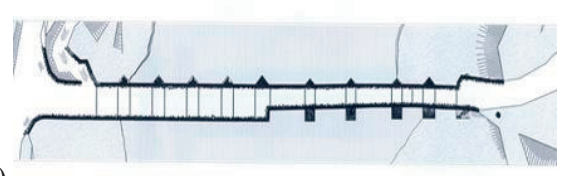

)

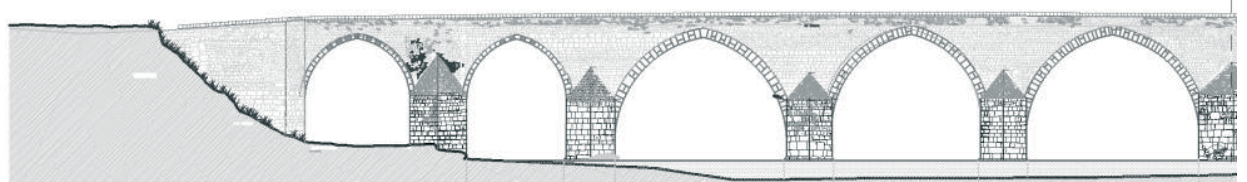

b)

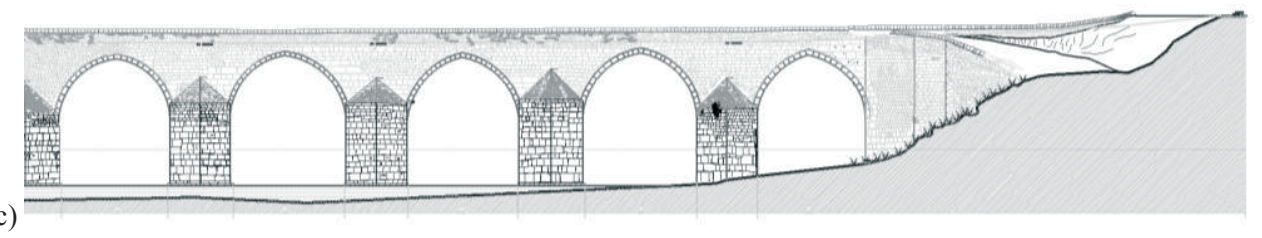

Fig. 3. Plane view on the bridge b-c) upstream elevation in two parts

The width of a bridge deck changes significantly. In the first five arches, it is between $9,69 \mathrm{~m}-10,20 \mathrm{~m}$ while the other sector is of $5,45 \mathrm{~m}-6,24 \mathrm{~m}$ breadth, see fig. 2 . In the construction, arches and copings are made from clean cut stone. Spandrel surfaces and railings are made of smaller blocks or rubble manufacturing. The niches passing the spans are double centered and lancet arched. Its flood splitters on upstream face are trianglecased, pyramidal cone. Railings whose significant part is genuine is covered by lancet copings. As it is seen in Fig. 2-3, in downstream face, there are four toes consisting of the remaining parts of abutments related to previous periods [4].

During the restoration of the bridge completed in 2009, scours in its abutments were filled, the plaster layer on arches was removed with scraper, bridge joints were renewed, the blanks in bridge texture emerging with the impact of water were filled with pozzolanic based material via injection method, flooring layer was renewed after asphalt coating on the bridge was removed [5].

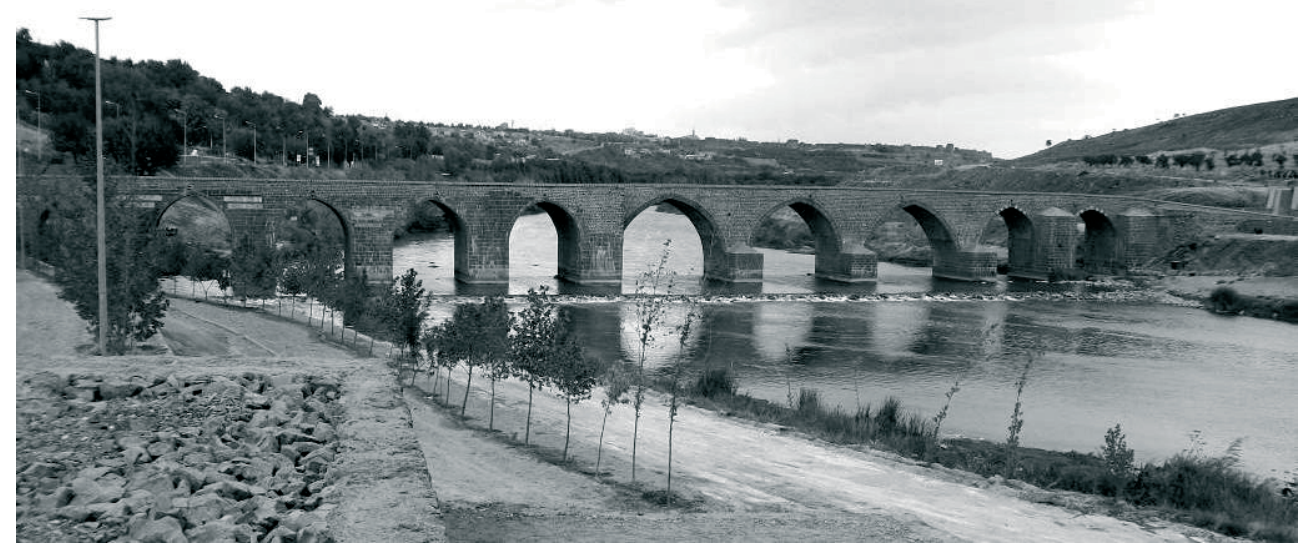

Fig. 3. Upstream elevation of Bridge, [6] 
It is not by mistake that arch bridges aesthetically dominate over other bridge shapes. The arch has a very important technical advantage. It is possible to construct a bridge arc so that the main element is in a dominated compressive state, with negligibly few remaining internal forces. This was the reason for building hundreds or even thousands ancient bridges erected mainly as road bridges or aqueducts.

The common availability of stone and brick contributed to an extensive construction of arched bridges in the Roman and Byzantine Empires. There is an arch bridge in Diyarbakir which can come from the period of the Persian Empire, therefore, it may be even older. It is obvious that brick and stone elements have always been perfect for compression, significantly weaker for tension and shearing, see Fig. 4.

The construction has undergone different repairs because of destructions in various periods. Visual integrity, material compatibility and original texture loss of the construction partially demolished due to wrong restorations are tried to be regained to the bridge with new intervention and applications.

\section{Properties of the protection}

For the protection of the construction and its transfer to future with confidence, it became inevitable to make some regulations that fit to its original historical role and intended use. With the works in this context, radical precautions were taken for example the removal of concrete manufactured later and the closing of bridge for pedestrian motor vehicle traffic in order to prevent abrasions due to vehicular traffic. Besides, for abrasions and deteriorations on abutments and arches, some improvement works were implemented.

It was also decided to avoid the use of hydro-isolation, simply because it would be a form of contemporary aggression to this historic monument, although small leakages are observed. This decision is a result of used in Turkey the concept of conservation which can be briefly evokes: bring the historic structure to the previous state and role. There are known other approaches to similar problems. An example is the use of hydro-insulation on the Charles Bridge (Karlův most in Czech tongue) in Prague. It is worth mentioning that many of historic bridges of historically different periods were refurbished in the manner.

\subsection{Pedestrianization of the bridge}

The first step towards the beginning of restoration works is the pedestrianization of the bridge. Afterwards, it was aimed that the bridge wasn't exposed to heavy live loads like car, truck, an alternative bridge was built and the restoration was completed in such a way that the existing bridge will be open only for touristic visits. Thus, deformations on the bridge that heavy live loads caused were prevented, Fig. 4.
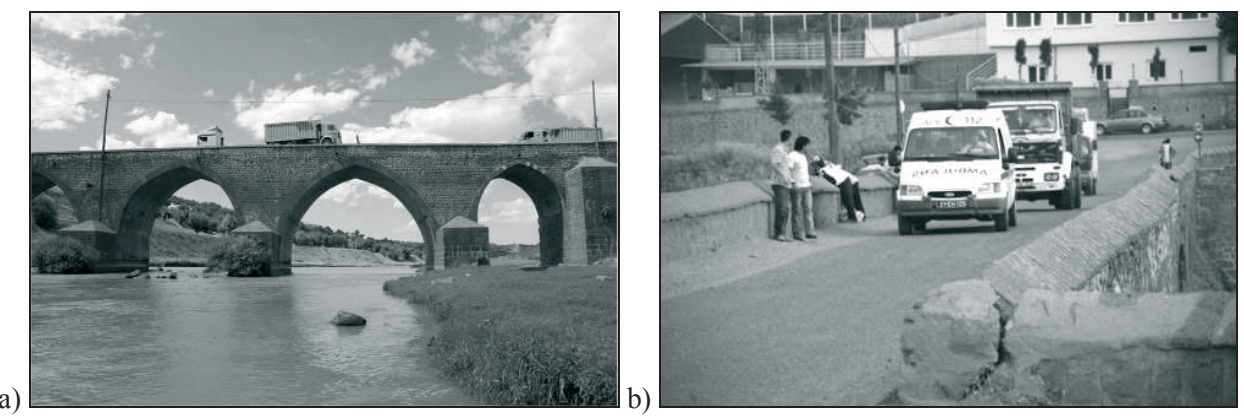

Fig. 4. Examples of moving loads before restoration a) side view b) longitudinal view 
There are not preserved corner columns with lamps enlightenment. Designed to railing on the bridge, nowadays does not satisfy the conditions of serviceability, namely safety for users. The lack of stone strengthening of river embankments is observed at the bridge.

\subsection{Restoration of abutment}

On the ground where abutments are settled, non linear flow of river water causes their undulation, whirlpool and irregularity of water bed. This resulted a big scours on abutments, the bridge foundation was confronted with serious conveying problem.

Due to these scours, serious discharges occurred on the grounds of abutments, Fig.5.a. Besides, splits, cracks and partly breakages occurred on the lower arrays of abutments because of direct abrasion of water and the decrease and increase of its flow, Fig. 5.b. This issue reached to serious texture losses with the breakage of existing linking clips in some abutments. During restoration, first of all, grounds and its ambient were purified from loam and foreign elements. It was reinforced by basalt prepared in original size by means of staggering with a specific height. As in present, these stones are connected each other with iron clips. Clips settled in slotted hollows on each two stones with lead enabled both that stones resisted against water by interconnecting and the basic carrying system of structure strengthened. In this way, strengthening work was performed in abutment and flood splitters that both ground and scours caused, the complementation of texture and surface on abutments are carried out, Fig. 5.c.

a)
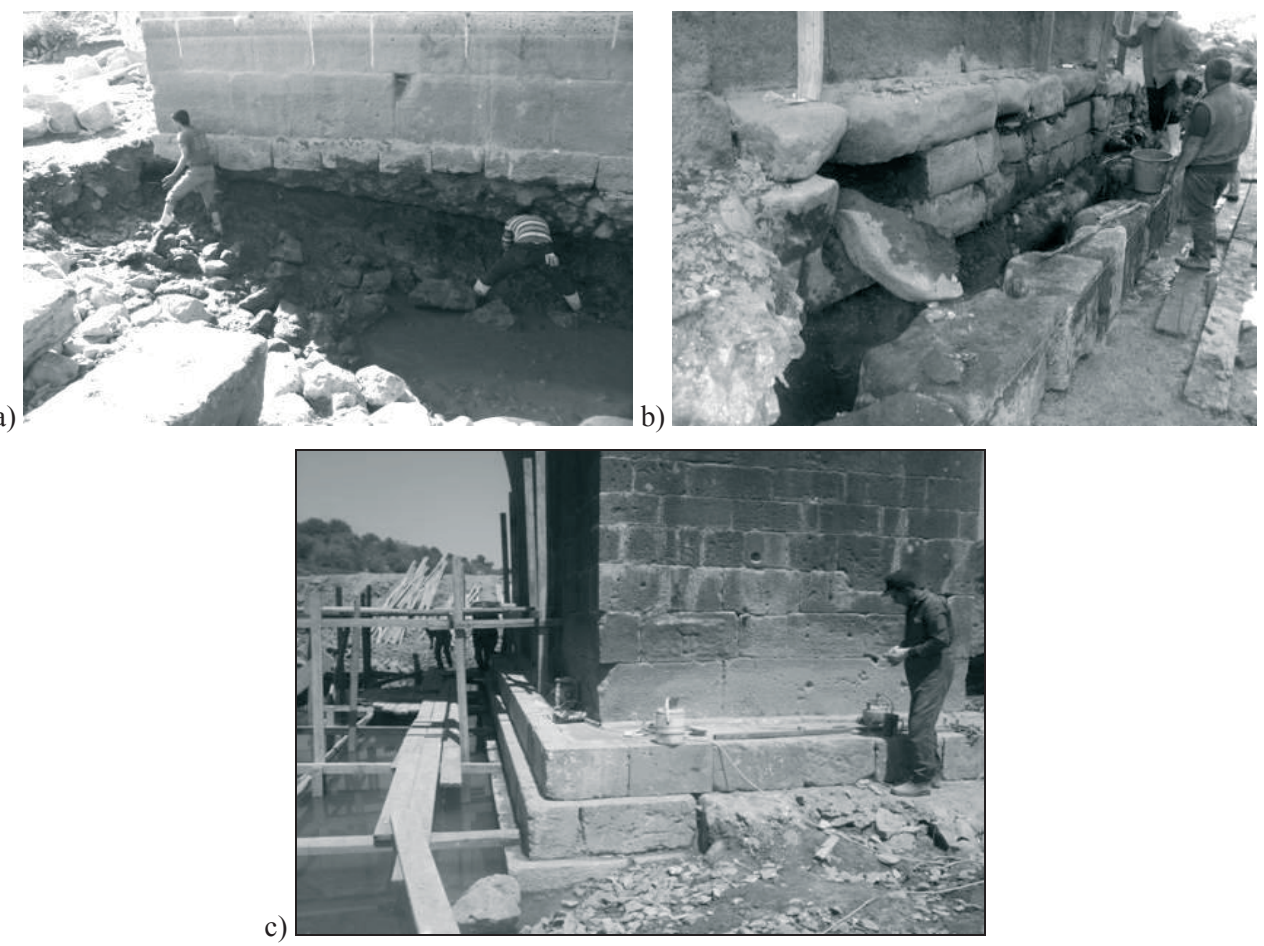

Fig. 5. Conservation works a) discharges on the grounds b-c) splits, cracks and breakages 


\subsection{Application on the arches}

Arch and spandrel stones that had structural deteriorations were removed by being numbered; the sound ones were used again during reconstruction. Instead of decaying, melting and disconnecting stones, the complementation was carried out by being used the same type of stones. Cement based joints seen in spandrel and arches were cleaned by being scraped without detriment to the original texture with the help of small item chisels and wire brushing, Fig. 6.a. Plasters on the original brick surface inner side of arches were cleaned by pen plaster, original brick texture and brick barrel vault coverings braided on original square order were revealed, Fig. 6.b. Plaster parts between brick and joint were cleaned without detriment to the material by means of compressed air and fine-lead metal pen and with injection air, dusts on the surface were taken.
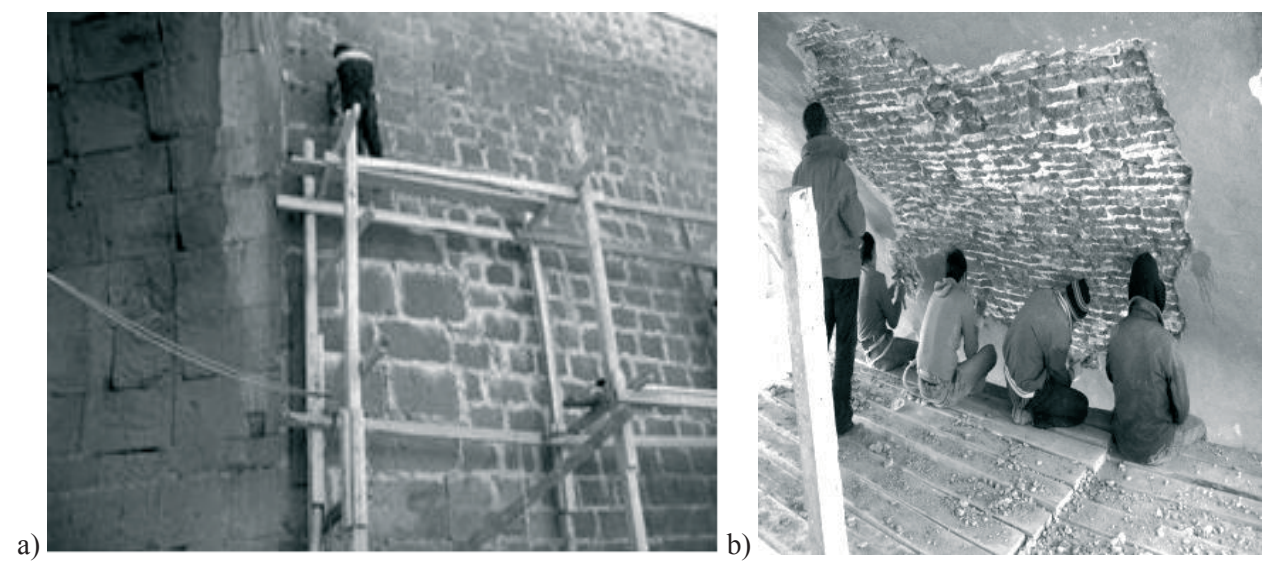

Fig. 5. The cleaning process a) joints, by being scraped b) cleaning of plasters

\subsection{Reveling of concrete layer}

The reveling of non original concrete layer, Fig. 6, is a highly important step in terms of both esthetics and authenticity and engineering in the meaning of unnecessary distributed load. In fact, $39 \mathrm{~cm}$ thickness concrete layer, Fig. 7, creates a distributed load with about 0.96 ton $/ \mathrm{m}^{2}$ size on this historical bridge which has $172 \mathrm{~m}$ length and whose width varies from $10 \mathrm{~m}$ to $6 \mathrm{~m}$. On the other hand, with the removal of concrete layer, the emergence of original flooring becomes quite happy and good issue in terms of the health of restoration, Fig. 8 - 10 .

a)
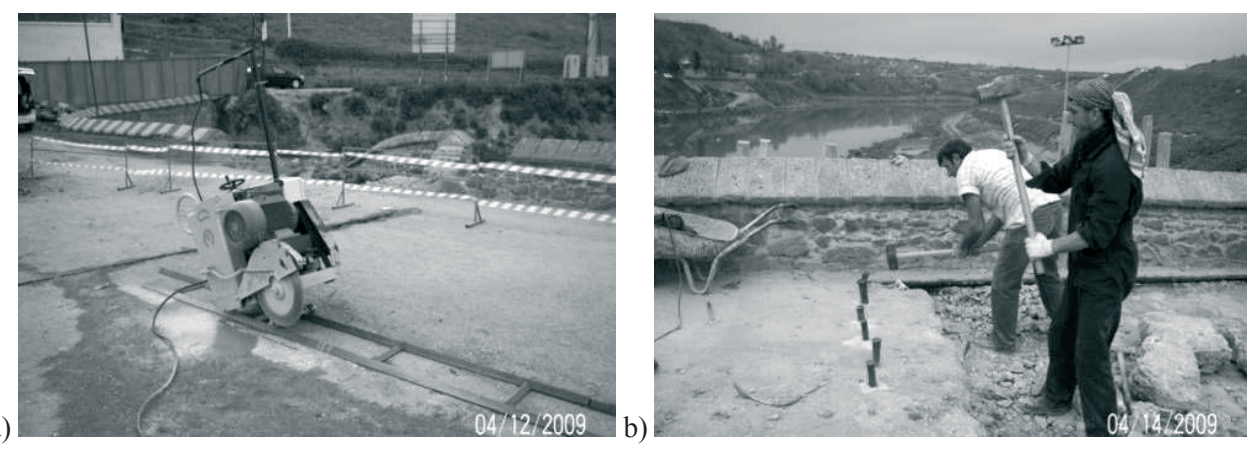

Fig. 6. a-b) revelling of concrete layer 

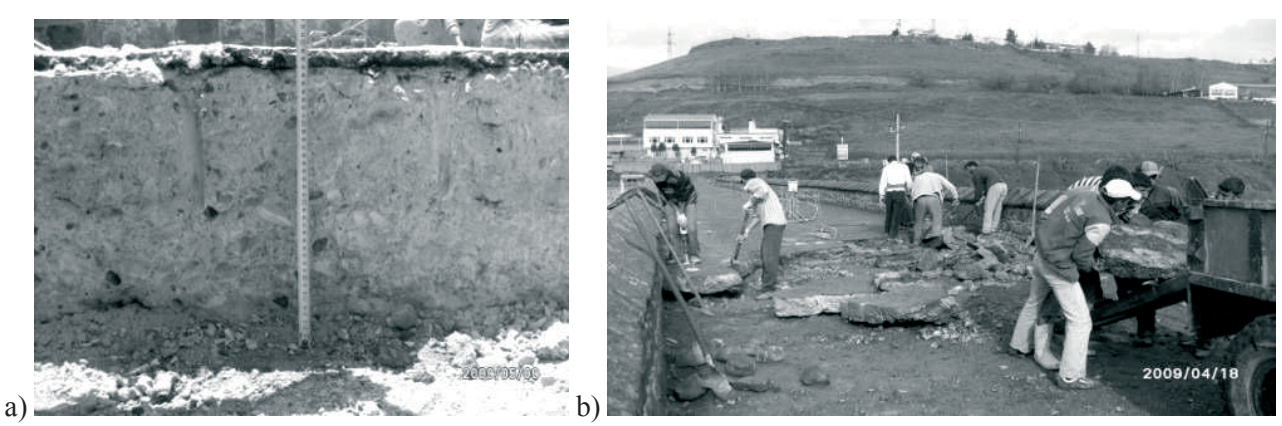

Fig. 7. a-b) $39 \mathrm{~cm}$ of concrete layer
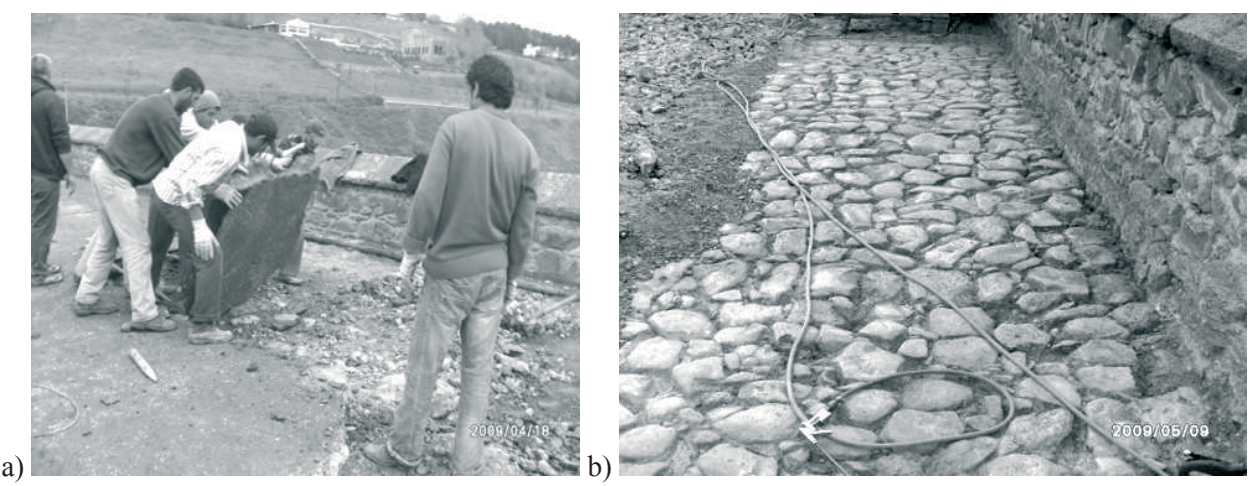

Fig. 8. a-b) The emergence of original flooring
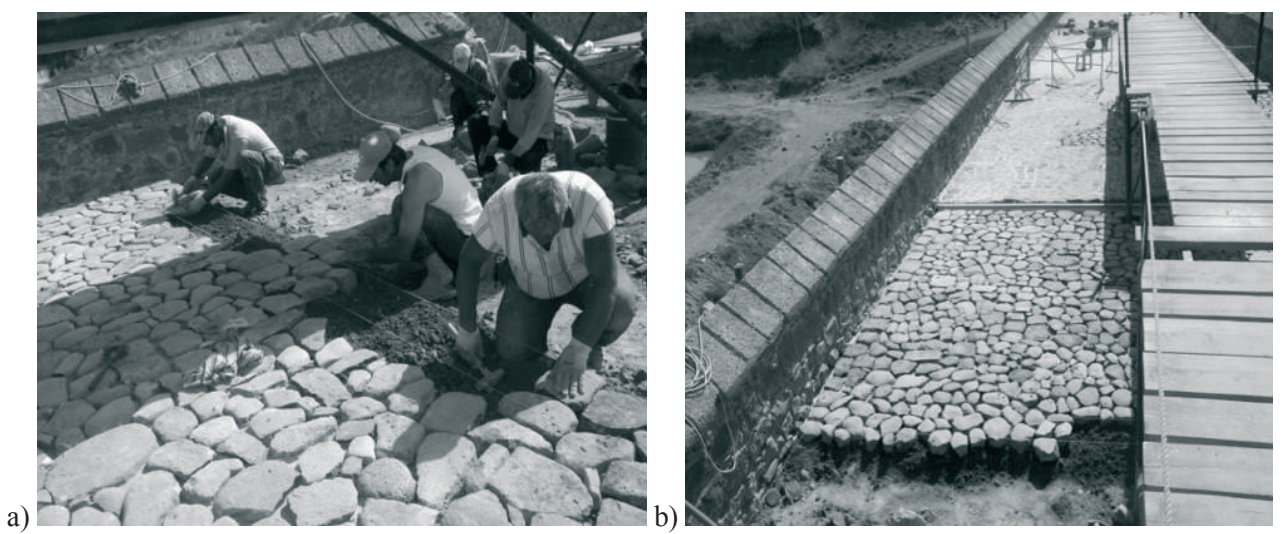

Fig. 8. a-b) The restoration of original flooring in accordance with its original

\section{Conclusion}

In the region that has continental climate, summer-winter temperature difference $(+45 /-15)$ reaches to 60 centigrade degree, day-night temperature difference $(+15 /-5)$ reaches to 20 centigrade degree. The volume expansion and shrinkages that this condition causes are one of important reasons of deformation on abutments. On the other hand, if the dates when the Bridge was built are taken into consideration, it is obvious that the calculated loads didn't go beyond the caravans and people. However, until a long time ago 
of the beginning of restoration works, it exposed to heavy live loads like truck, car and it became another factor deforming the carrying system of the bridge. Basically, the restoration work completed with the following steps such as the pedestratization of the bridge, the complementation of texture and surface losses on abutments, scraping of plasters on arch surfaces lose cohesiveness, become decomposition and the opening and reconstruction of non original joints, the reveling of non original texture and the reconstruction of texture with original size and order by depending on findings after this, the filling of internal slumps on the bridge formed based on time and external factors by means of injection method also showed a good protection model because it was pedestrianized with the construction of alternative bridge. The removal of the effects of unnecessary live and distributed load serves as a good model in terms of sustainability. All these works became an important step for the transfer of bridge to future with confidence.

\title{
References
}

1. Beysanoğlu, Ş., “Anıtları ve Kitabeleri ile Diyarbakır Tarihi”, Ankara, 1996

2. Çulpan, C., "Türk Taş Köprüleri”, Turkish Historical Society Publications, Ankara, 2002.

3. İlter, F., “Osmanlılara Kadar Anadolu Türk Köprüleri” Ankara, 1978.

4. https://www.google.com.tr/maps/@37.8872215,40.2265649,17z?hl=tr (access date: 04.01.2016)

5. Sert H., Halifeoğlu M., Dalkılıç N., Halifeoğlu Z., "Tarihi Diyarbakir Dicle (On Gözlü) Köprüsü’Nün Onarimi, Güçlendirilmesi Ve Yeniden Kullanimi”, International Participation Strengthening of Historical Monuments and Safely Transferred to the Future Symposium-2 Diyarbakır, 2009.

6. Republic Of Turkey General Directore Of Highways http://www.kgm.gov.tr/SiteCollection Documents/KGMdocuments/MerkezBirimler/SanatYapilariDairesiBaskanligi/Calismalar/Tarihik $\% \mathrm{C} 3 \% \mathrm{~B} 6 \mathrm{pr} \% \mathrm{C} 3 \% \mathrm{BClercalismalar}$.pdf (access date: 04.01.2016)

\section{Protection of Ten-Eyed Bridge in Diyarbakır}

\author{
Ibrahim Baran Karasin, Ercan Isik \\ Department of Civil Engineering, Faculty of Engineering and Architecture, Bitlis Eren University, \\ e-mail: ibkarasin@beu.edu.tr,eisik@beu.edu.tr
}

\begin{abstract}
Ten-Eyed Bridge, that is one of the most important historical and cultural symbols of Diyarbakir, having lasted till today, became an example of this prosperous heritage. However, various interventions and deteriorations have occurred in the construction within long time due to the impact of human and nature. Because of the considerable temperature difference arising due to continental climate of the region as well as damages like the change of conditions of use, amortizations in bearing constructional components in contact with water have emerged. In this study, with the purpose of ensuring future existence of Ten-Eyed Bridge, adopted methods for structural and physical deteriorations and protection works were examined.
\end{abstract}

Keywords: Historic Ten-Eyed Bridge, Heritage Protection, Diyarbakır. 